\title{
Impact of 13-valent pneumococcal conjugate vaccine (PCV13) in a pandemic similar to the $2009 \mathrm{H} 1 \mathrm{~N} 1$ in the United States
}

Lisa J McGarry ${ }^{1}$, Kristen E Gilmore ${ }^{1 *}$, Jaime L Rubin ${ }^{1}$, Keith P Klugman², David R Strutton ${ }^{3}$ and Milton C Weinstein ${ }^{1,4}$

\begin{abstract}
Background: High rates of bacterial coinfection in autopsy data from the $2009 \mathrm{H} 1 \mathrm{~N} 1$ influenza ("flu") pandemic suggest synergies between flu and pneumococcal disease (PD) during pandemic conditions, and highlight the importance of interventions like the 13-valent pneumococcal conjugate vaccine (PCV13) that may mitigate the impact of a pandemic.
\end{abstract}

Methods: We used a decision-analytic model, estimated from published sources, to assess the impact of pediatric vaccination with PCV13 versus the 7-valent vaccine (PCV7) on PD incidence and mortality in a normal flu season (10\% flu incidence) and in a pandemic similar to 2009-2010 H1N1 (20\% flu incidence, mild virulence, high impact in children). Both direct and indirect (herd) effects against PD were considered. Effectiveness of PCV13 was extrapolated from observed PCV7 data, using assumptions of serotype prevalence and PCV13 protection against the 6 serotypes not in PCV7. To simulate 2009-2010 H1N1, autopsy data were used to estimate the overall proportion of flu deaths with bacterial coinfections. By assuming that increased risk of death during the pandemic occurred among those with comorbidity (using obesity as proxy) and bacterial coinfections primarily due to S. pneumoniae or S. aureus, we estimated the proportion co-infected among all (fatal and non-fatal) flu cases (7.6\% co-infected with any organism; 2.2\% with S. pneumoniae). PD incidence, mortality, and total healthcare costs were evaluated over a 1-year horizon.

Results: In a normal flu season, compared to PCV7, PCV13 is expected to prevent an additional 13,400 invasive PD (IPD) cases, 399,000 pneumonia cases, and 2,900 deaths, leading to cost savings of $\$ 472 \mathrm{M}$. In a pandemic similar to 2009-2010 H1N1, PCV13 would prevent 22,800 IPD cases, 872,000 pneumonia cases, and 3,700 deaths, resulting in cost savings of $\$ 1.0 \mathrm{~B}$ compared to PCV7.

Conclusions: In a flu pandemic similar to the 2009-2010 H1N1, protection against the 6 additional serotypes in PCV13 would likely be effective in preventing pandemic-related PD cases, mortality, and associated costs.

Keywords: Pneumococcal disease, Influenza, H1N1 pandemic

\section{Background}

The 1918 influenza pandemic resulted in at least 20 million deaths worldwide, with some estimates as high as 100 million [1-4]. Over the succeeding decades, considerable efforts have been made to determine why mortality during the 1918 pandemic was

\footnotetext{
* Correspondence: kristen.gilmore@optum.com

'Optumlnsight, One Main Street, Suite 1040, Cambridge, MA 02142, USA

Full list of author information is available at the end of the article
}

so high and ensure that such a catastrophic outcome could be avoided in future pandemics. At the time of the pandemic, researchers suspected complications of bacterial pneumonia as the primary driver of excess influenza deaths [5]. This theory has recently gained support from autopsy studies of 1918 influenza victims that have established a link between secondary bacterial infection and death by confirming the presence of bacterial pneumonia in nearly all autopsy samples examined $[6,7]$.

\section{Biomed Central}


In June 2009, the World Health Organization (WHO) declared the novel influenza A H1N1 virus A/California/ $7 / 2009$ (referred to as 2009-2010 H1N1) as a pandemic, making it the world's fourth influenza pandemic in the last century and the first in 40 years [8]. By November 2009, WHO reported more than onehalf million confirmed novel H1N1 influenza cases and more than six thousand deaths [9]. Several studies of H1N1-infected patients worldwide have confirmed high levels of bacterial coinfection, and there is evidence to suggest that bacterial coinfection led to excess H1N1 deaths. A retrospective analysis of hospitalized patients with laboratory-confirmed $\mathrm{H} 1 \mathrm{~N} 1$ in Malaysia found 14 of 50 patients $(28 \%)$ to have a bacterial coinfection [10], and in a study of 199 H1N1infected patients in Argentina, S. pneumoniae was detected in $56 \%$ of the $39 \mathrm{H} 1 \mathrm{~N} 1$ cases that resulted in hospitalization or death [11]. An autopsy study in Brazil found bacterial coinfection in 8 of 21 (38\%) samples [12], an autopsy study of H1N1 victims in New York City confirmed the presence of bacterial pneumonia in 18 of 33 (55\%) samples examined for pulmonary bacterial infection [13], and a Centers for Disease Control and Prevention (CDC) H1N1 autopsy study reported evidence of bacterial infection in 22 of 77 (29\%) samples [14].

The synergies observed between bacterial pneumonia and influenza with respect to morbidity and death during influenza pandemics suggest pediatric pneumococcal vaccination may mitigate the public health impact of an influenza pandemic by preventing bacterial coinfections with S. pneumoniae [15]. Since approval of the 7-valent pneumococcal conjugate vaccine (PCV7) in 2000 for pediatric use in children aged up to 59 months [16], PCV7 has resulted in a marked reduction in the incidence of invasive pneumococcal disease (IPD) [17-19] and pneumonia [20] in both the vaccinated and nonvaccinated populations (i.e. due to indirect protection). In a previously published study, we estimated that a fully-implemented PCV7 pediatric vaccination program would avoid 1.2 million cases of IPD and pneumonia and save $\$ 7.3$ billion in a pandemic of similar severity to 1918 [15].

In 2010, the 13-valent pneumococcal conjugate vaccine (PCV13) replaced PCV7 as the recommended pediatric pneumococcal vaccine [21]. PCV13 is more expensive than $\mathrm{PCV} 7$, but protects against the seven serotypes covered by PCV7 plus an additional six serotypes, including 19A. PCV13 vaccination was not in place during the 2009-2010 influenza season, and the possible benefits of the vaccine in a pandemic of this magnitude are unknown. The current study explores the impact of vaccinating children against the additional six serotypes in PCV13 both during a normal influenza season and during a pandemic similar to the 2009-2010 H1N1.

\section{Methods}

\section{Overview}

In a previously-published study, we constructed a decision-analytic model to assess the impact of pediatric PCV7 vaccination versus a policy of no PCV vaccination in the context of an influenza pandemic of 1918 severity [15]. That model was updated to assess the impact of pediatric PCV13 vaccination versus continued vaccination with PCV7 during a normal season [22] and influenza pandemic of 1918 severity (unpublished analysis). For the current analysis, the model was adapted to assess the impact of pediatric PCV13 vaccination versus continued vaccination with PCV7 during an influenza pandemic similar to the 2009-2010 H1N1. Clinical and economic outcomes related to IPD (meningitis and bacteremia) and allcause pneumonia were evaluated over a 1 -year time horizon to reflect one influenza season, and longterm outcomes of events occurring during the oneyear period were projected to the lifetime of the model population. Future costs and health outcomes attributable to cases occurring in the index year were discounted to present values using a 3\% annual discount rate [23].

The model considers outcomes of pneumococcal disease only; morbidity, mortality, and costs of influenza without pneumococcal coinfection were assumed to be unaffected by pneumococcal vaccination and are not considered. Outcomes include cases of pneumococcal disease, pneumococcal-associated deaths, and related costs. In all analyses, we compared a policy of pediatric PCV13 vaccination to one of pediatric PCV7 vaccination in populations with fully-implemented vaccine programs.

\section{Estimation}

Pneumococcal disease incidence and mortality, and vaccine efficacy

Estimates of vaccine coverage, pneumococcal disease incidence and mortality, and vaccine effectiveness have been previously published in a study of the public health and economic impact of PCV13 in the United States (see Appendix) [22]. Briefly, age-specific pneumococcal disease incidence and mortality rates were estimated from Active Bacterial Core Surveillance (ABCs) data [17,24-26] and other published observational studies [20,27-34]. Direct efficacy and expected indirect effects were estimated from published and unpublished age- and serotype-specific data from the $\mathrm{ABCs}$ and other published sources [20,24,25,34-38]. Estimates of vaccine efficacy for children aged 2-4 years 
take into account the waning effectiveness of the vaccine. Indirect effects represent the expected benefit to older children and adults from a fully implemented vaccination program (approximately seven years postvaccine introduction).

\section{Influenza incidence}

We estimated the influenza incidence in a pandemic similar to the 2009-2010 H1N1 from data published by the CDC. According to CDC estimates, approximately 61 million US residents were infected with H1N1 during the 2009-2010 influenza season, indicating a cumulative incidence of $20 \%$ in a population of approximately 300 million [39]. We estimated agespecific incidence of influenza using data from a study that predicted the true prevalence of H1N1 based on laboratory-confirmed specimens and modeling techniques [40]. We applied the age-specific odds ratios calculated from the prevalence study to the CDC estimates of influenza incidence to arrive at influenza incidence estimates of $44.3 \%$ for children aged $0-4$ years, $51.7 \%$ for the $5-17$ years age group, $13.5 \%$ for the 18-49 years age group, $7.6 \%$ for the $50-64$ years age group, and $2.5 \%$ for those aged $65+$ years. The CDC estimates that approximately 12,470 deaths were associated with the 2009-2010 H1N1, indicating a case-fatality of approximately $0.2 \%$ [39].

\section{Pneumococcal disease incidence and mortality in a pandemic}

Data on pneumococcal disease incidence during the 2009-2010 H1N1 pandemic are limited. To estimate the incidence of pneumococcal disease and simulate the potential acceleration of pneumococcal disease transmission in a pandemic similar to the 2009-2010 H1N1, we estimated the proportion of influenza cases with bacterial coinfection [14]. Autopsy data were available to estimate the proportion of influenza deaths with bacterial coinfection, from which the proportion of coinfection among all H1N1 cases (i.e., both fatal and non-fatal) was derived.

Because the proportion of influenza deaths with coinfection at autopsy is driven both by rates of coinfection and excess mortality due to coinfection, a number of assumptions were necessary to estimate the rate of coinfection among all H1N1 cases. First, we assumed that the underlying increased risk of death due to influenza among those with comorbidity, using obesity as a proxy, was unrelated to coinfection. Second, we assumed that the excess risk of death due to coinfection during the pandemic was equal among those with and without comorbidity. These two assumptions imply that there are no synergies between comorbidity and coinfection with respect to mortality. Third, we assumed that obesity is not associated with risk of influenza or coinfection, such that the prevalence of obesity and morbid obesity among those with influenza is expected to be the same as that in the U.S. population. We further assumed that bacterial coinfections were primarily due to $S$. pneumoniae or $S$. aureus. Details regarding the equations used to estimate the probability of coinfection are provided in the Appendix. In summary, we derived the following equation for the proportion of H1N1 cases co-infected:

$$
\begin{aligned}
& \gamma=\left\{F_{c}\left[1+P_{o}\left(R R_{o}-1\right)+P_{b}\left(R R_{b}-1\right)-1\right]\right\} / \\
&\left\{P_{o}\left(R R_{o}-1\right)+P_{b}\left(R R_{b}-1\right)\right\}
\end{aligned}
$$

where $\gamma$ is the probability of bacterial coinfection with any organism among all influenza patients, $F_{c}$ is the fraction of deaths from bacterial coinfection with any organism, $\mathrm{P}_{\mathrm{o}}$ is the prevalence of obesity, $\mathrm{P}_{\mathrm{b}}$ is the prevalence of morbid obesity, $R R_{o}$ is the risk ratio for influenza-related death for those obese versus normal weight, and $R R_{b}$ is the risk ratio for influenzarelated death for those morbidly obese versus normal weight.

Based on pediatric autopsy data from the CDC, we assumed that $43 \%$ of patients dying from 2009-2010 H1N1 influenza were co-infected with any bacterial organism $\left(\mathrm{F}_{\mathrm{c}}\right)$, and that $30 \%$ of patients with any bacterial coinfection were co-infected with $S$. pneumoniae [41]. We estimated the relative risk of death for obese $\left(R R_{o}: 3.1\right)$ and morbidly obese $\left(R_{\mathrm{b}}: 7.6\right)$ individuals compared to individuals of normal weight from a case-cohort study of patients hospitalized during the 2009-2010 H1N1 pandemic [42]. Based on obesity data from the National Health and Nutrition Examination Survey (NHANES), we assumed $33.8 \%$ of the adult population in the United States to be obese (body mass index $[\mathrm{BMI}] \geq 30$ ) and $20 \%$ of the obese population to be morbidly obese $(\mathrm{BMI} \geq 40)$ [43]. We then solved for the proportion of all H1N1 influenza patients who also had a bacterial coinfection, resulting in estimates of $7.6 \%$ of patients with any bacterial coinfection and $2.2 \%$ of patients co-infected with $S$. pneumoniae. We used the same model to estimate the risk of bacterial coinfection in a normal influenza season (1.5\%). The multiplier on pneumococcal disease incidence during a pandemic influenza season of 5.01 was calculated as the ratio of the pandemic- versus normal-season prevalence of coinfection.

It was assumed that background pneumococcal disease incidence and mortality, as described above in the section on "Pneumococcal Disease Incidence and Mortality, and Vaccine Efficacy", represent the actual 
risk of pneumococcal disease during a normal influenza season and therefore any synergies between pneumococcal disease and influenza would be captured in the observed incidence. Therefore, we did not make any additional assumptions about synergies between influenza and pneumococcal disease when estimating the model for a normal influenza season.

\section{Costs and utilities}

All pneumococcal disease costs were estimated from published sources as described previously; to maintain consistency with previous analyses, costs are in $\$ 2008$ US [22].Briefly, costs associated with non-hospitalized pneumonia for children aged $<5$ years and IPD and hospitalized pneumonia for all ages were adapted from Ray et al., 2009 [44]. Costs of long-term consequences of meningitis were adapted from lifetime costs of deafness and disability for children $<5$ years and adjusted by discounted life-expectancy. Nonhospitalized pneumonia costs for persons aged $\geq 5$ years were estimated as the total of an office visit, chest radiograph, blood culture, and one course of antibiotics [22].

The costs used for PCV7 and PCV13 are consistent with the prices at the time of PCV13 launch as used in previous publications. The average cost for a single dose of PCV13 in the US was assumed to be $\$ 100$, while the average cost for a single dose of PCV7 was assumed to be $\$ 73$ [22]. Both vaccines were assumed to have an administration cost of $\$ 11$ per dose [33].

Utilities, preference-based quality-of-life measures ranging from 0 to 1 , were incorporated by assigning a quality-adjusted life-year (QALY) decrement for each pneumococcal disease episode, as described previously [22].Lifetime costs and consequences (including lifeyears lost and permanent disabilities) attributable to a case of IPD were discounted to present value at an annual rate of $3 \%$.

\section{Analyses}

The model generates estimates of pneumococcal disease cases avoided, deaths averted, cost differences, and QALYs gained for a policy of PCV13 pediatric vaccination versus a policy of PCV7 pediatric vaccination. Cases and deaths averted were calculated as the difference in the total number of cases/deaths with PCV13 pediatric vaccination minus the total number of cases/deaths with PCV7 vaccination. Cost differences were calculated by subtracting total costs for a policy of PCV13 pediatric vaccination (the cost of vaccinating children with PCV13 less any cost offsets associated with avoiding disease), from total costs associated with a PCV7 pediatric vaccination policy. Analyses were conducted under assumptions meant to replicate the 2009-2010 H1N1 pandemic and also under normal influenza conditions to serve as a comparison to the pandemic. All results are presented from the payer perspective, and therefore consider only direct medical costs.

Direct and indirect effectiveness of PCV13 were estimated by extrapolating from the PCV7 experience, so there is considerable uncertainty regarding the expected benefits of PCV13 in unvaccinated populations. We therefore performed sensitivity analyses to assess how changes in assumptions regarding indirect effectiveness would change model results by, in turn, assuming: 1) PCV13 vaccine has no indirect effectiveness against either IPD or pneumonia, 2) PCV13 vaccine has indirect effectiveness against IPD and hospitalized pneumonia, but no indirect effectiveness against non-hospitalized pneumonia, or 3) PCV13 vaccine has indirect effectiveness against IPD and both hospitalized and non-hospitalized pneumonia. Because our estimation of the prevalence of bacterial co-infection was based on a number of assumptions, we also performed a sensitivity analysis in which the prevalence of co-infection was reduced by half.

\section{Results}

\section{Base-case}

The model predicts that 3.6 million children aged birth to $<1$ year will receive the pneumococcal vaccine over a 1-year time horizon; an additional 12.2 million children aged $1-<5$ years will receive direct protection from vaccination in prior years. In a normal influenza season, the model predicts that with a PCV7 pediatric vaccination program we would expect 40,800 cases of IPD and 4.52 million cases of allcause pneumonia; vaccinating children with PCV13 would reduce these numbers to 27,400 IPD cases and 4.12 million all-cause pneumonia cases. In a pandemic similar to the 2009-2010 H1N1, a PCV7 pediatric vaccination policy would lead to an expected 62,100 IPD cases and 9.95 million all-cause pneumonia cases. A policy of PCV13 vaccination reduces this to 39,300 cases of IPD and 9.08 million cases of all-cause pneumonia. Table 1 displays the numbers of additional cases of pneumococcal disease avoided with PCV13 versus PCV7, by age group, for both influenza scenarios.

In a normal influenza season, PCV13 is expected to prevent an estimated 2,900 deaths compared to PCV7; 4,200 IPD and 23,200 hospitalized pneumonia deaths are expected with PCV7, while 3,000 IPD and 21,500 hospitalized pneumonia deaths are expected with PCV13. For a pandemic similar to 2009-2010 H1N1, PCV13 is expected to prevent an estimated 3,700 deaths compared to PCV7; 5,400 IPD and 27,300 hospitalized 
Table 1 Pneumococcal cases avoided with PCV13 vs. PCV7 pediatric vaccination in normal and pandemic influenza seasons Normal influenza season

\begin{tabular}{|c|c|c|c|c|c|c|c|}
\hline & $0-1$ yrs & $2-4$ yrs & $5-17 y r s$ & $18-49$ yrs & $50-64$ yrs & $65+y r s$ & Total \\
\hline IPD & 1,900 & 1,100 & 400 & 3,600 & 2,500 & 3,800 & 13,400 \\
\hline Hospitalized pneumonia & 10,000 & 2,000 & 3,600 & 17,500 & 2,800 & 22,000 & 57,400 \\
\hline Non-Hospitalized pneumonia & 87,900 & 34,300 & 76,400 & 97,600 & 12,000 & 33,000 & 341,200 \\
\hline Total & 99,300 & 37,400 & 80,500 & 118,700 & 17,300 & 58,900 & 412,000 \\
\hline \multicolumn{8}{|c|}{ Pandemic similar to $2009-2010 \mathrm{H} 1 \mathrm{~N} 1$} \\
\hline & $0-1$ yrs & $2-4$ yrs & $5-17 y r s$ & $18-49$ yrs & $50-64$ yrs & $65+y r s$ & Total \\
\hline IPD & 5,300 & 3,100 & 1,400 & 5,500 & 3,300 & 4,200 & 22,800 \\
\hline Hospitalized pneumonia & 26,400 & 5,500 & 11,100 & 27,000 & 3,600 & 24,200 & 97,700 \\
\hline Non-Hospitalized pneumonia & 242,500 & 94,500 & 234,600 & 150,300 & 15,700 & 36,300 & 773,800 \\
\hline Total & 274,200 & 103,100 & 247,000 & 182,800 & 22,600 & 64,800 & 894,300 \\
\hline
\end{tabular}

IPD, Invasive pneumococcal disease.

pneumonia deaths are expected with PCV7, compared with 3,800 IPD and 25,200 hospitalized pneumonia deaths for PCV13. The numbers of pneumococcal deaths averted for IPD and hospitalized pneumonia for each influenza scenario are presented in Figure 1 (note: discrepancies in the difference calculations are due to rounding).

Vaccination program costs are estimated at $\$ 1.1$ billion for PCV7 and \$1.5 billion for PCV13. In a normal influenza season, pneumococcal disease costs associated with the PCV7 and PCV13 vaccination policies are $\$ 7.8$ billion and $\$ 7.0$ billion, respectively. For a pandemic similar to 2009-2010 H1N1, PCV7 and PCV13 vaccination programs are projected to result in pneumococcal disease costs of $\$ 12.7$ billion and $\$ 11.3$ billion, respectively. The breakdown of medical cost savings due to vaccination with PCV13, by presentation of pneumococcal disease, is presented in Table 2 for both influenza scenarios.

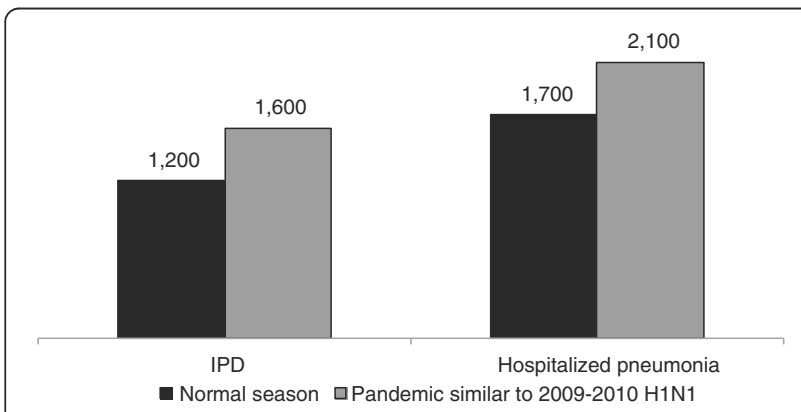

Figure 1 Pneumococcal deaths averted for PCV13 vs. PCV7 pediatric vaccination in normal and pandemic influenza seasons.

\section{Sensitivity analyses}

Assuming indirect protection against IPD and no indirect protection against all-cause pneumonia, PCV13 vaccination continues to result in significant cost savings compared to PCV7, for both a normal influenza season and an influenza pandemic season similar to 2009-2010 H1N1. For a pandemic season, if PCV13 is assumed to offer indirect protection only against IPD but not all-cause pneumonia, medical cost savings due to fewer cases of pneumococcal disease nevertheless more than offset the incremental cost of the PCV13 vaccination program compared to PCV7. The cost of the PCV13 vaccination program in a normal influenza season is not entirely offset by medical cost savings under the assumptions of no indirect protection against pneumonia; however, PCV13 vaccination remains cost-effective compared with PCV7 vaccination at a cost of $\$ 4,300$ per QALY gained. Given the uncertainty in the proportion of all $\mathrm{H} 1 \mathrm{~N} 1$ influenza patients who also had a bacterial coinfection, the base-case assumption was halved, resulting in a multiplier of 2.5 on pneumococcal disease incidence during a pandemic influenza season. The cost savings associated with the PCV13 vaccination program under this scenario were approximately two-thirds that of the cost savings in the base case. The results of the sensitivity analyses are presented in Table 3.

\section{Discussion}

High rates of bacterial coinfection in autopsy data from the 2009-2010 H1N1 influenza pandemic suggest synergies between influenza and pneumococcal disease in pandemic conditions. While influenza vaccination remains the primary tool to control the significant burden of influenza during both seasonal epidemics and 
Table 2 Cost savings for PCV13 vs. PCV7 pediatric vaccination in normal and pandemic influenza seasons

\begin{tabular}{lccccc}
\hline Influenza scenario & IPD & Hospitalized pneumonia & Non-Hospitalized pneumonia & Vaccination & Total \\
\hline Normal season & $\$ 235 \mathrm{M}$ & $\$ 509 \mathrm{M}$ & \$96 M & $(\$ 367 \mathrm{M})$ & \$472 M \\
Pandemic similar to 2009-2010 H1N1 & $\$ 358 \mathrm{M}$ & $\$ 812 \mathrm{M}$ & $\$ 213 \mathrm{M}$ & $(\$ 367 \mathrm{M})$ & \$1.02 B \\
\hline
\end{tabular}

IPD, Invasive pneumococcal disease; $M$, Million; B, Billion.

pandemic seasons, pneumococcal vaccination also has the potential to mitigate the impact of pandemic influenza. During the 2009-2010 H1N1 pandemic, protection against the six additional serotypes in PCV13 compared to PCV7 likely would have prevented a portion of the pandemic-related pneumococcal cases, deaths, and costs.

In a typical influenza season, a PCV13 vaccination policy is expected to prevent an additional 13,400 IPD cases, 399,000 all-cause pneumonia cases, and 2,900 deaths, leading to cost savings of $\$ 472$ million when compared to a PCV7 vaccination policy. We previously estimated that the PCV7 vaccination program in the US was cost saving for a normal influenza season, reducing pneumococcal-related costs by $\$ 1.6$ billion per year; therefore the total cost savings of PCV13 versus a policy of no pneumococcal vaccination can be estimated at $\$ 2.4$ billion per year. In a relatively mild pandemic similar to 2009-2010 H1N1, PCV13 is expected to prevent
22,800 IPD cases (1.7x normal season), 872,000 all-cause pneumonia cases (2.2x normal season), 3,700 deaths, and save $\$ 1.0$ billion (2.2x normal season) compared to PCV7.

Our study is subject to a number of limitations inherent in the study design. First, the decision-analytic model is necessarily a highly simplified representation of the disease transmission and outcomes of pneumococcal disease. Although we accounted for some differences in treatment and outcomes using age stratification, we recognize that the U.S. population and healthcare delivery system are highly heterogeneous and may not be well represented by the relatively simple structure of this model. We also note that data used to estimate vaccine effectiveness and outcomes were derived and synthesized from a variety of sources, and this process of selection and interpretation is subject to bias. Although extensive sensitivity analyses to evaluate the effect of alternative parameter choices on our outcomes showed no change in the overall conclusions, we

Table 3 Sensitivity analyses around indirect effectiveness of PCV13 and co-infection assumptions in normal and pandemic influenza seasons

\begin{tabular}{|c|c|c|c|c|}
\hline \multicolumn{5}{|l|}{ Normal season } \\
\hline & Base-Case & IPD indirect effects only & No indirect effects & Halve $\%$ with bacterial co-infection \\
\hline \multicolumn{5}{|l|}{ Cases avoided } \\
\hline IPD & 13,400 & 13,400 & 2,100 & 13,400 \\
\hline Hospitalized pneumonia & 57,400 & 5,000 & 5,000 & 57,400 \\
\hline Non-Hospitalized pneumonia & 341,200 & 62,300 & 62,400 & 341,200 \\
\hline Deaths averted & 2,900 & 1,200 & 40 & 2,900 \\
\hline Cost /(savings) & $\$(472) M$ & $\$ 82 M$ & $\$ 299 M$ & $(\$ 472 M)$ \\
\hline QALYs gained & 41,524 & 18,953 & 4,484 & 41,524 \\
\hline Cost per QALY gained & dominant & $\$ 4,300$ & $\$ 66,800$ & dominant \\
\hline \multicolumn{5}{|c|}{ Pandemic similar to $2009-2010 \mathrm{H} 1 \mathrm{~N} 1$} \\
\hline & Base-Case & IPD indirect effects only & No indirect effects & Halve $\%$ with bacterial co-infection \\
\hline \multicolumn{5}{|l|}{ Cases avoided } \\
\hline IPD & 22,800 & 22,800 & 5,700 & 16,900 \\
\hline Hospitalized pneumonia & 97,700 & 13,700 & 13,900 & 72,600 \\
\hline Non-Hospitalized pneumonia & 773,800 & 170,800 & 171,900 & 504,000 \\
\hline Deaths averted & 3,700 & 1,600 & 110 & 3,200 \\
\hline Cost/(savings) & (\$ 1.02 B) & $(\$ 130 \mathrm{M})$ & $\$ 180 \mathrm{M}$ & $(\$ 676 \mathrm{M})$ \\
\hline QALYs gained & 51,637 & 25,671 & 4,844 & 44,023 \\
\hline Cost per QALY gained & dominant & dominant & $\$ 37,100$ & dominant \\
\hline
\end{tabular}

IPD, Invasive pneumococcal disease; $M$, Million; $B$, Billion; $Q A L Y$, Quality-adjusted life-year. 
recognize that different assumptions may have yielded different results.

Costs used in this analysis were taken from published data and standard sources; the extent to which they reflect the true costs of administering medical care is unknown. Furthermore, this study was conducted from a third-party payer perspective rather than a societal perspective, and as such does not include costs of pneumococcal disease related to lost productivity, caregiver time, transportation, or other unreimbursed expenses. Inclusion of these costs presumably would have added substantially to the total cost burden of pneumococcal disease and the potential cost savings with PCV13. In addition, the model was estimated using U.S. data, and care should be used in generalizing our results to other settings and populations.

Because the data available to estimate pneumococcal coinfections were incomplete and based on autopsy data, a number of assumptions were necessary to convert these estimates of pneumococcal infection among influenza deaths to population estimates of coinfection. Although we attempted to be conservative in our assumptions, there remains a high level of uncertainty in these estimates. In particular, our calculations using obesity as a surrogate for all comorbidity is a simplification, and may not reflect the mechanism leading to excess deaths in groups such as those with asthma or immunosuppression, and pregnant women. Studies that examined obesity along with other comorbidities as a risk factor for poor outcomes in H1N1 have shown obesity to be the strongest and most consistent predictor. For example more than half of hospitalized H1N1 cases in California observed between April and August 2009 were obese and one-quarter morbidly obese [45], and obesity was identified as the strongest predictor of death in an analysis of hospitalized H1N1 cases in the United Kingdom (odds-ratio $=6.08 ; p=0.01$ ) [46]. We further note, that Morgan and colleagues [42] estimated the odds-ratios of death for obese and morbidly obese persons versus normal weight persons among patients with chronic medical conditions that are risk factors for poor influenza outcomes (as identified by the Advisory Committee on Immunization Practices [ACIP]) and among patients with no chronic medical conditions. They found the odds of death to be significantly elevated only among obese and morbidly obese persons without chronic medical conditions; suggesting that the increased risk associated with comorbidity may be captured by the increase risk due to obesity in patient with both conditions.

It is also possible that our assumption of independence between obesity/comorbidity and bacterial coinfection as causes of death in persons with influenza is not valid. However, we note that there is considerable overlap in the comorbidities considered risk factors for both adverse pneumococcal disease outcomes and adverse influenza outcomes by ACIP [21,47], suggesting that these conditions associated with poor influenza outcome also increase risk in the presence of pneumococcal infection. If there are synergies between comorbidity and coinfection, as suggested by a study in Malaysia [10], the rate of coinfection may be overestimated; however we found that even when we halved our estimate of the rate of coinfection, vaccination remained cost-saving in an assumed pandemic similar to 2009-2010 H1N1.

\section{Conclusion}

Our model suggests that, had PCV13 vaccination been implemented prior to the recent 2009-2010 H1N1 pandemic, the protection provided would have prevented more than 3,500 deaths and saved $\$ 1.0$ billion. Although the 2009-2010 H1N1 pandemic proved to be far less severe than initial reports suggested, even in a relatively mild pandemic similar to the 2009-2010 H1N1, protection against the six additional serotypes in PCV13 would likely be effective in preventing pandemic-related pneumococcal disease cases, mortality, and associated costs.

\section{Appendix}

This section contains detailed descriptions of model parameters (Table 4) as well as additional explanation around the assumptions and methodology for calculating probabilities of coinfection.

\section{Calculation of Probability of Coinfection}

Definition of variables:

$\gamma=$ probability of coinfection (any organism)

$\mathrm{F}_{\mathrm{c}}=$ fraction of deaths with coinfection (any organism)*

$\mathrm{m}_{\mathrm{c}}=$ mortality with coinfection, normal weight

$\mathrm{m}_{\mathrm{o}}=$ mortality with coinfection, obese

$\mathrm{m}_{\mathrm{b}}=$ mortality with coinfection, morbidly obese

$\mathrm{RR}_{\mathrm{o}}=$ relative risk for death, obese vs. normal weight *

$\mathrm{RR}_{\mathrm{b}}=$ relative risk for death, morbidly obese vs. normal weight *

$\mathrm{P}_{\mathrm{o}}=$ prevalence of obesity *

$\mathrm{P}_{\mathrm{b}}=$ prevalence of morbid obesity *

$\mathrm{M}=$ total mortality among flu infected

* denotes variables with known or estimated values

Assumptions:

1. All influenza deaths are attributable to either obesity or coinfection.

2. In the absence of coinfection, obese and morbidly obese persons have progressively greater mortality than persons of normal weight.

3. Excess mortality owing to coinfection is the same for obese and non-obese persons. 
Table 4 Parameter Values

\begin{tabular}{|c|c|c|c|c|c|c|}
\hline \multirow[t]{2}{*}{ Parameter } & \multicolumn{6}{|c|}{ Age group (years) } \\
\hline & $0-<2$ & $2-4$ & $5-17$ & $18-49$ & $50-64$ & $65+$ \\
\hline \multicolumn{7}{|c|}{ Annual non-pandemic baseline incidence rates $/ 100,000^{a}$} \\
\hline Pneumococcal meningitis & 3.54 & 0.98 & 0.27 & 0.71 & 1.37 & 2.39 \\
\hline Pneumococcal bacteremia & 33.9 & 13.2 & 2.16 & 6.97 & 18.5 & 35.5 \\
\hline All-cause pneumonia & 8,749 & 7,752 & 1,648 & 750 & 328 & 2,163 \\
\hline Percent of meningitis that results in deafness ${ }^{b}$ & $13 \%$ & $13 \%$ & $6 \%$ & $13 \%$ & $13 \%$ & $13 \%$ \\
\hline Percent of meningitis that results in disability ${ }^{b}$ & $7 \%$ & $7 \%$ & $5 \%$ & $7 \%$ & $7 \%$ & $7 \%$ \\
\hline \multicolumn{7}{|l|}{ Case-Fatality Rates } \\
\hline Pneumococcal meningitis ${ }^{c}$ & $6.9 \%$ & $4.0 \%$ & $10.0 \%$ & $10.4 \%$ & $11.4 \%$ & $23.8 \%$ \\
\hline Pneumococcal bacteremia ${ }^{c}$ & $0.9 \%$ & $0.4 \%$ & $4.2 \%$ & $6.2 \%$ & $11.3 \%$ & $15.7 \%$ \\
\hline All-cause hospitalized pneumonia ${ }^{d}$ & $0.4 \%$ & $0.2 \%$ & $0.3 \%$ & $1.2 \%$ & $2.5 \%$ & $6.3 \%$ \\
\hline \multicolumn{7}{|c|}{ Direct effects (\% reduction in disease at time of vaccination) ${ }^{e}$} \\
\hline IPD & $49.8 \%$ & - & - & - & - & - \\
\hline All-cause hospitalized pneumonia & $16.2 \%$ & - & - & - & - & - \\
\hline vAll-cause non-hospitalized pneumonia & $3.8 \%$ & - & - & - & - & - \\
\hline \multicolumn{7}{|l|}{ Indirect effects (\% reduction in disease $)^{f}$} \\
\hline IPD & $32.7 \%$ & $39.4 \%$ & $34.4 \%$ & $34.5 \%$ & $24.5 \%$ & $27.4 \%$ \\
\hline All-cause hospitalized pneumonia & $22.5 \%$ & $0.0 \%$ & $9.2 \%$ & $11.3 \%$ & $8.7 \%$ & $6.9 \%$ \\
\hline All-cause non-hospitalized pneumonia & $6.2 \%$ & $0.0 \%$ & $4.7 \%$ & $5.9 \%$ & $3.7 \%$ & $3.4 \%$ \\
\hline \multicolumn{7}{|l|}{ Direct Medical Costs $(\$ 2008)$} \\
\hline Meningitis episode ${ }^{g}$ & $\$ 17,048$ & $\$ 17,048$ & - & - & - & - \\
\hline Bacteremia episode ${ }^{g}$ & $\$ 3,253$ & $\$ 3,253$ & - & - & - & - \\
\hline Cost of invasive disease episode ${ }^{g}$ & - & - & $\$ 12,738$ & $\$ 17,956$ & $\$ 22,135$ & $\$ 17,216$ \\
\hline Lifetime cost of deafness $^{\mathrm{h}}$ & $\$ 96,788$ & $\$ 96,788$ & $\$ 91,663$ & $\$ 73,530$ & $\$ 48,435$ & $\$ 35,261$ \\
\hline Lifetime cost of disability ${ }^{\text {h }}$ & $\$ 499,409$ & $\$ 499,409$ & $\$ 472,965$ & $\$ 379,402$ & $\$ 249,915$ & $\$ 181,940$ \\
\hline Hospitalized pneumonia episode ${ }^{h}$ & $\$ 7,276$ & $\$ 7,276$ & $\$ 4,994$ & $\$ 9,248$ & $\$ 10,148$ & $\$ 9,872$ \\
\hline Non-hospitalized pneumonia episode & $\$ 233$ & $\$ 233$ & $\$ 308$ & $\$ 308$ & $\$ 308$ & $\$ 308$ \\
\hline \multicolumn{7}{|l|}{ Vaccine Price (per dose) } \\
\hline PCV7 & $\$ 73$ & - & - & - & - & - \\
\hline PCV13 & $\$ 100$ & - & - & - & - & - \\
\hline Vaccine administration & $\$ 11$ & - & - & - & - & - \\
\hline \multirow[t]{2}{*}{ QALY Inputs (all ages), } & Meningitis & Bacteremia & $\begin{array}{l}\text { Hospitalized } \\
\text { Pneumonia }\end{array}$ & $\begin{array}{l}\text { Non-Hospitalized } \\
\text { Pneumonia }\end{array}$ & $\begin{array}{c}\text { Deafness } \\
\text { (utility) }\end{array}$ & $\begin{array}{c}\text { Disability } \\
\text { (utility) }\end{array}$ \\
\hline & 0.023 & 0.008 & 0.006 & 0.004 & 0.73 & 0.68 \\
\hline
\end{tabular}

Note: Comprehensive information related to estimation and references is available in two previously published studies [15,22].

a. Incidence rate estimates assume a steady state utilizing 2007 as the baseline year. IPD incidence estimated from unpublished ABCs data provided by Matt Moore [24]. Hospitalized pneumonia incidence estimated from Grijalva [20] with updated estimates for kids $<5$ years from January 16, 2010 issue of the MMWR. Non-hospitalized pneumonia incidence estimated from analyses of National Ambulatory Medical Care Survey (NAMCS) and National Hospital Ambulatory Medical Care Survey (NHAMCS) 2006 (U.S. Dept. of Health and Human Services, National Center for Health Statistics [27,28].

b. Estimated from Lieu [29] and Shepard [30].

c. Adapted from ABCs Report: Emerging Infections Program Network. Streptococcus pneumoniae 2007 and Tsai [32].

d. Fatality rates estimated from National Vital Statistics report [32]; converted to case-fatality rates by applying rate of death to incidence rates from Grijalva et al. [20]. e. IPD estimated from serotype coverage of PCV13 from ABCs data assuming 94\% efficacy against those types. Hospitalized pneumonia adapted from PCV7 efficacy in Black [35] adjusted for PCV13 serotype coverage. Non-hospitalized pneumonia adapted from PCV7 efficacy in Hansen [36] adjusted for PCV13 serotype coverage. f. IPD estimated from serotype-specific prevalence from $A B C s$ data. Pneumonia estimated using age-specific reductions in disease observed after the introduction of PCV7 in 2000, adjusted by serotype coverage.

g. Estimates for all ages adapted from Ray et al. [44].

h. Estimated from Ray et al. [44] for children < $<$ years; adjusted by relative difference in discounted life expectancy to obtain lifetime costs for older age groups. i. Estimates for $<5$ years adapted from Ray et al. [44]; estimates for $>5$ years assumes 1 physician visit, $46 \%$ of patients receive chest radiograph, blood count and culture, and one course of zithromycin.

j. QALY decrements adapted from Melegaro and Edmunds [48], a cost-effectiveness study in England and Wales that synthesized estimates from various primary sources. k. Utilities for chronic health states estimated from retrospective studies of meningococcal complications $[49,50]$. 
4. The risks of death associated with coinfection and either obesity or morbid obesity are additive.

5. The incidence of influenza and the prevalence of coinfection among obese and morbidly obese people are the same as for people of normal weight.

\section{Risk of death}

There are 6 groups: 3 obesity categories, each of which can be co-infected or not. The overall probability of death is the weighted average over these 6 groups. Assume those with neither comorbidities nor coinfections are not at risk of death:

$$
\begin{aligned}
\mathrm{M}= & \gamma\left(1-\mathrm{P}_{\mathrm{o}}-\mathrm{P}_{\mathrm{b}}\right) * \mathrm{~m}_{\mathrm{c}}+\gamma \mathrm{P}_{\mathrm{o}}\left(\mathrm{m}_{\mathrm{c}}+\mathrm{m}_{\mathrm{o}}\right)+\gamma \mathrm{P}_{\mathrm{b}}\left(\mathrm{m}_{\mathrm{c}}+\mathrm{m}_{\mathrm{b}}\right) \\
& +(1-\gamma) \mathrm{P}_{\mathrm{o}} \mathrm{m}_{\mathrm{o}}+(1-\gamma) \mathrm{P}_{\mathrm{b}} \mathrm{m}_{\mathrm{b}} \\
& =\gamma \mathrm{m}_{\mathrm{c}}+\mathrm{P}_{\mathrm{o}} \mathrm{m}_{\mathrm{o}}+\mathrm{P}_{\mathrm{b}} \mathrm{m}_{\mathrm{b}}
\end{aligned}
$$

\section{Mortality with coinfection}

Because we assume that mortality due to obesity is additive to mortality due to coinfection, and that mortality due to coinfection is independent of obesity, the probability of death among persons with coinfection is as follows:

$$
\mathrm{A}=\left(1-\mathrm{P}_{\mathrm{o}}-\mathrm{P}_{\mathrm{o}}\right) * \mathrm{~m}_{\mathrm{c}}+\mathrm{P}_{\mathrm{o}}\left(\mathrm{m}_{\mathrm{c}}+\mathrm{m}_{\mathrm{o}}\right)+\mathrm{P}_{\mathrm{b}}\left(\mathrm{m}_{\mathrm{c}}+\mathrm{m}_{\mathrm{b}}\right)
$$

Since the probability of coinfection is further assumed to be independent of obesity status, the probability of dying and being co-infected is $\gamma^{*} \mathrm{~A}$.

\section{Fraction of deaths with coinfection}

$$
\begin{aligned}
\mathrm{F}_{\mathrm{c}}= & \gamma \mathrm{A} / \mathrm{M} \\
& =\gamma\left(\mathrm{m}_{\mathrm{c}}-\mathrm{P}_{\mathrm{o}} \mathrm{m}_{\mathrm{o}}+\mathrm{P}_{\mathrm{b}} \mathrm{m}_{\mathrm{b}}\right) /\left(\gamma \mathrm{m}_{\mathrm{c}}-\mathrm{P}_{\mathrm{o}} \mathrm{m}_{\mathrm{o}}+\mathrm{P}_{\mathrm{b}} \mathrm{m}_{\mathrm{b}}\right)
\end{aligned}
$$

\section{Relative risk (RR) for death, obese vs. normal weight}

$$
\begin{aligned}
R_{\mathrm{o}}= & {\left[(1-\gamma) \mathrm{m}_{\mathrm{o}}+\gamma\left(\mathrm{m}_{\mathrm{o}}+\mathrm{m}_{\mathrm{c}}\right)\right] / \gamma \mathrm{m}_{\mathrm{c}} } \\
= & \left(\mathrm{m}_{\mathrm{o}}+\gamma \mathrm{m}_{\mathrm{c}}\right) / \gamma \mathrm{m}_{\mathrm{c}}
\end{aligned}
$$

\section{Relative risk for death, morbidly obese vs. normal weight}

$$
\begin{aligned}
\mathrm{RR}_{\mathrm{b}}= & {\left[(1-\gamma) \mathrm{m}_{\mathrm{b}}+\gamma\left(\mathrm{m}_{\mathrm{b}}+\mathrm{m}_{\mathrm{c}}\right)\right] / \gamma \mathrm{m}_{\mathrm{c}} } \\
= & \left(\mathrm{m}_{\mathrm{b}}+\gamma \mathrm{m}_{\mathrm{c}}\right) / \gamma \mathrm{m}_{\mathrm{c}}
\end{aligned}
$$

\section{Solution of equations (3)-(5):}

$$
\begin{aligned}
\gamma= & \left\{\mathbf{F}_{\mathbf{c}}\left[\mathbf{1}+\mathbf{P}_{\mathbf{o}}\left(\mathbf{R R}_{\mathbf{o}}-\mathbf{1}\right)+\mathbf{P}_{\mathbf{b}}\left(\mathbf{R R}_{\mathbf{b}}-\mathbf{1}\right)-\mathbf{1}\right]-\mathbf{1}\right\} / \\
& \left\{\mathbf{P}_{\mathbf{o}}\left(\mathbf{R R}_{\mathbf{o}}-\mathbf{1}\right)+\mathbf{P}_{\mathbf{b}}\left(\mathbf{R R}_{\mathbf{b}}-\mathbf{1}\right)\right\}
\end{aligned}
$$

(Technical note: We have 3 equations (3)-(5), with 4 unknowns $\left(\gamma, \mathrm{m}_{\mathrm{b}}, \mathrm{m}_{\mathrm{o}}\right.$, and $\left.\mathrm{m}_{\mathrm{c}}\right)$, but $\mathrm{m}_{\mathrm{b}}, \mathrm{m}_{\mathrm{o}}$, and $\mathrm{m}_{\mathrm{c}}$ can only be determined relative to each other - not absolutely from the data available.)

\section{Calculation}

$$
\begin{aligned}
& \mathrm{F}_{\mathrm{c}}=.43 \\
& \mathrm{RR}_{\mathrm{o}}=3.1 \\
& \mathrm{RR}_{\mathrm{b}}=7.6 \\
& \mathrm{P}_{\mathrm{O}}=0.138 \\
& \mathrm{P}_{\mathrm{b}}=0.2 \\
& \gamma(\text { any organism })=\{0.43[1+(0.138)(2.1)+(0.2)(6.6)]-1\} / \\
& \{(0.1 .38)(2.1)(6.6)\} \\
& =0.1222 / 1.6 \\
& =0.0759
\end{aligned}
$$

Assuming 30\% are S. pneumoniae:

$$
\gamma(\text { S. pneumoniae })=0.0759 * .30=0.0228
$$

\section{Abbreviations}

ABCs: Active bacterial core surveillance; ACIP: Advisory committee on immunization practices; BMI: Body mass index; CDC: Centers for disease control and prevention; IPD: Invasive pneumococcal disease;

NHANES: National health and nutrition examination survey; PCV13: 13-Valent pneumococcal conjugate vaccine; PCV7: 7-Valent pneumococcal conjugate vaccine; WHO: World health organization

\section{Competing interests}

This study was sponsored by Wyeth, which was acquired by Pfizer Inc. in 2009. DRS is an employee of Pfizer; LJM, KEG, JLR, KPK, and MCW served as paid consultants to Pfizer for this study.

\section{Authors' contributions}

LJM participated in the study design and methodology, participated in estimating model parameters, and helped to draft the manuscript. KEG performed the model programming and participated in estimating mode parameters. JLR participated in the study design and methodology, participated in estimating model parameters and helped to draft the manuscript. KPK provided clinical input to the study design and vetted model parameter estimation. DRS participated in the design of the study and oversaw study methodology and model estimation. MCW was a key contributor to model design and vetted the model structure and analyses. All authors read and approved the final manuscript.

\section{Acknowledgements}

This study was sponsored by Wyeth, which was acquired by Pfizer Inc. in 2009. Lisa J. McGarry and Kristen E. Gilmore are employees of Optumlnsight (formerly Innovus), and Jaime L. Rubin is a former employee of Optumlnsight (formerly Innovus), who were paid consultants to Pfizer in connection with this study. Keith P. Klugman and Milton C Weinstein were contracted by OptumInsight (formerly Innovus), as paid consultants in connection with this study.

\section{Author details}

'Optumlnsight, One Main Street, Suite 1040, Cambridge, MA 02142, USA. 2Department of Global Health, Rollins School of Public Health, Emory University, 1518 Clifton Road, N.E - Room 720, Atlanta, GA 30322, USA. ${ }^{3}$ Pfizer, 500 Arcola Road, Collegeville, PA 19426, USA. ${ }^{4}$ Center for Health Decision Science, Harvard School of Public Health, Harvard University, 718 Huntington Avenue, Boston, MA 02115, USA.

Received: 7 August 2012 Accepted: 23 April 2013

Published: 21 May 2013 


\section{References}

1. Kamps BS, Hoffmann C, Preiser W: Influenza report 2006. http://www. influenzareport.com Accessed December 24, 2008.

2. Trust for America's Health: Pandemic flu and the potential for U.S. economic recession: a state-by-state analysis, March 2007. http://healthyamericans.org/ reports/flurecession/ Accessed December 24, 2008.

3. Taubenberger JK, Morens DM: 1918 Influenza: the mother of all pandemics. http://www.cdc.gov/ncidod/EID/vol12no01/05-0979.htm Accessed December 24, 2008.

4. Johnson NP, Mueller J: Updating the accounts: global mortality of the 1918-1920 "Spanish" influenza pandemic. Bull Hist Med 2002, 76(1):105-115.

5. Muir R, Haswell Wilson G: Observations on influenza and its complications. Br Med J 1919, 1(3027):3-5.

6. Morens DM, Taubenberger JK, Fauci AS: Predominant role of bacterial pneumonia as a cause of death in pandemic influenza: implications for pandemic influenza preparedness. J Infect Dis 2008, 198(7):962-970.

7. Sheng ZM, Chertow DS, Ambroggio X, McCall S, Przygodzki RM, Cunningham RE, Maximova OA, Kash JC, Morens DM, Taubenberger JK: Autopsy series of 68 cases dying before and during the 1918 influenza pandemic peak. Proc Natl Acad Sci USA 2011, 108(39):16416-16421.

8. Chan M: World now at the start of 2009 influenza pandemic. Statement to the press by the World Health Organization. 2009. http://www.who.int/mediacentre/ news/statements/2009/h1n1_pandemic_phase6_20090611/en/ Accessed Apri 1, 2010.

9. World Health Organization: Pandemic (H1N1) 2009 - update 74. http://www. who.int/csr/don/2009_11_13/en/index.html Accessed November 18, 2012.

10. Dhanoa A, Fang NC, Hassan SS, Kaniappan P, Rajasekaram G: Epidemiology and clinical characteristics of hospitalized patients with pandemic influenza A (H1N1) 2009 infections: the effects of bacterial coinfection. Virol J 2011, 8:501.

11. Palacios G, Hornig M, Cisterna D, Savji N, Bussetti AV, Kapoor V, Hui J, Tokarz R, Briese T, Baumeister E, Lipkin Wl: Streptococcus pneumoniae coinfection is correlated with the severity of H1N1 pandemic influenza. PLoS One 2009, 4(12):e8540.

12. Mauad T, Hajjar LA, Callegari GD, da Silva LF, Schout D, Galas FR, Alves VA, Malheiros DM, Auler JO Jr, Ferreira AF, Borsato MR, Bezerra SM, Gutierrez PS, Caldini ET, Pasqualucci CA, Dolhnikoff M, Saldiva PH: Lung pathology in fatal novel human influenza a (H1N1) infection. Am J Respir Crit Care Med 2010, 181:72-79.

13. Gill JR, Sheng ZM, Ely SF, Guinee DG, Beasley MB, Suh J, Deshpande C Mollura DJ, Morens DM, Bray M, Travis WD, Taubenberger JK: Pulmonary pathologic findings of fatal 2009 pandemic influenza a/H1N1 viral infections. Arch Pathol Lab Med 2010, 134:235-243.

14. Centers for Disease Control and Prevention: Bacterial coinfections in lung tissue specimens from fatal cases of 2009 pandemic influenza a (H1N1) united states, May - august 2009. MMWR Morb Mortal Wkly Rep 2009, 58(38):1071-1074.

15. Rubin JL, McGarry L, Klugman KP, Strutton DR, Gilmore KE, Weinstein MC: Public health and economic impact of vaccination with 7-valent pneumococcal vaccine (PCV7) in the context of the annual influenza epidemic and a severe influenza pandemic. BMC Infect Dis 2010, 10:14

16. Advisory Committee on Immunization Practices: Preventing pneumococcal disease among infants and young children: recommendations of the advisory committee on immunization practices (ACIP). MMWR Recomm Rep 2000, 49(RR-9):1-35.

17. Centers for Disease Control and Prevention: Active Bacterial Core Surveillance (ABCs) Report: Emerging Infections Program Network. Streptococcus pneumoniae 2006. http://www.cdc.gov/abcs/reports-findings/survreports/ spneu06.html Accessed December 24, 2008

18. Centers for Disease Control and Prevention: Active Bacterial Core Surveillance (ABCs) Report: Emerging Infections Program Network. Streptococcus pneumoniae 1998. http://www.cdc.gov/abcs/reports-findings/survreports/ spneu98.html Accessed December 24, 2008.

19. Centers for Disease Control and Prevention: Progress in introduction of pneumococcal conjugate vaccine--worldwide, 2000-2008. MMWR Morb Mortal Wkly Rep 2008, 57(42):1148-1151.

20. Grijalva CG, Nuorti JP, Arbogast PG, Martin SW, Edwards KM, Griffin MR: Decline in pneumonia admissions after routine childhood immunisation with pneumococcal conjugate vaccine in the USA: a time-series analysis. Lancet 2007, 369(9568):1179-1186.
21. Centers for Disease Control and Prevention: Licensure of a 13-valent pneumococcal conjugate vaccine (PCV13) and recommendations for Use among children - advisory committee on immunization practices (ACIP), 2010. MMWR Morb Mortal Wkly Rep 2010, 59(09):258-261.

22. Rubin JL, McGarry LJ, Strutton DR, Pelton SI, Gilmore KE, Weinstein MC Public health and economic impact of the 13-valent pneumococcal conjugate vaccine (PCV13) in the united states. Vaccine 2010, 28(48):7634-7643.

23. Gold MR, Siegel JE, Russell LB, Weinstein MC: Cost-effectiveness in health and medicine. New York: Oxford University Press; 1996.

24. Centers for Disease Control and Prevention: Active Bacterial Core Surveillance (ABCs) program (unpublished data, March 2009) - provided by Matt Moore. MD.

25. >Pilishvili T, Lexau C, Farley MM, Hadler J, Harrison LH, Bennett NM, Reingold A, Thomas A, Schaffner W, Craig AS, Smith PJ, Beall BW, Whitney CG, Moore MR, Active Bacterial Core Surveillance/Emerging Infections Program Network: Sustained reductions in invasive pneumococcal disease in the era of conjugate vaccine. $J$ Infect Dis 2010, 201(1):32-41.

26. Centers for Disease Control and Prevention: Active Bacterial Core Surveillance (ABCS) Report: Emerging Infections Program Network. Streptococcus pneumoniae 2007. http://www.cdc.gov/abcs/reports-findings/survreports/ spneu07.html Accessed December 24, 2008

27. U.S. Department of Health and Human Services, National Center for Health Statistics: National Ambulatory Medical Care Survey. 2006.

28. U.S. Department of Health and Human Services, National Center for Health Statistics: National Hospital Ambulatory Medical Care Survey. 2006.

29. Lieu TA, Ray GT, Black SB, Butler JC, Klein JO, Breiman RF, Miller MA, Shinefield HR: Projected cost-effectiveness of pneumococcal conjugate vaccination of healthy infants and young children. JAMA 2000, 283(11):1460-1468

30. Shepard CW, Ortega-Sanchez IR, Scott RD II, Rosenstein NE, ABCs Team: Cost-effectiveness of conjugate meningococcal vaccination strategies in the United States. Pediatrics 2005, 115(5):1220-1232. 283

31. Tsai CJ, Griffin MR, Nuorti JP, Grijalva CG: Changing epidemiology of pneumococcal meningitis after the introduction of pneumococcal conjugate vaccine in the United States. Clin Infect Dis 2008, 46(11):1664-1672.

32. Miniño AM, Heron MP, Murphy SL, Kochankek KD: Deaths: Final Data for 2004. National Vital Statistics Reports, 55(19). Hyattsville, MD: National Center for Health Statistics; 2007

33. Ray GT, Whitney CG, Fireman BH, Ciuryla V, Black SB: Cost-effectiveness of pneumococcal conjugate vaccine- evidence from the first 5 years of use in the United States incorporating herd effects. Pediatr Infect Dis J 2006, 25(6):494-501.

34. Black S, Shinefield H, Fireman B, Lewis E, Ray P, Hansen JR, Elvin L, Ensor KM Hackell J, Siber G, Malinoski F, Madore D, Chang I, Kohberger R, Watson W, Austrian R, Edwards K, Northern California Kaiser Permanente Vaccine Study Center Group: Efficacy, safety, and immunogenicity of heptavalent pneumococcal conjugate vaccine in children. Pediatr Infect Dis J 2000, 19(3):187-195

35. Black SB, Shinefield HR, Ling S, Hansen J, Fireman B, Spring D, Noyes J, Lewis E, Ray P, Lee J, Hackell J: Effectiveness of heptavalent pneumococcal conjugate vaccine in children less than five years of age for prevention of pneumonia. Pediatr Infect Dis J 2002, 21(9):810-815.

36. Hansen J, Black S, Shinefield H, Cherian T, Benson J, Fireman B, Lewis E, Ray P, Lee J: Effectiveness of heptavalent pneumococcal conjugate vaccine in children younger than 5 years of age for prevention of pneumonia: updated analysis using world health organization standardized interpretation of chest radiographs. Pediatr Infect Dis J 2006, 25(9):779-781.

37. Zhou F, Shefer A, Kong Y, Nuorti JP: Trends in acute otitis media-related health care utilization by privately insured young children in the United States, 1997-2004. Pediatrics 2008, 121(2):253-260.

38. Zhou F, Kyaw MH, Shefer A, Winston CA, Nuorti JP: Health care utilization for pneumonia in young children after routine pneumococcal conjugate vaccine use in the United States. Arch Pediatr Adolesc Med 2007, 161(12):1162-1168

39. Centers for Disease Control and Prevention: Updated CDC Estimates of 2009 H1N1 Influenza Cases, Hospitalizations and Deaths in the United States, April 2009 - April 10, 2010. http://www.cdc.gov/h1n1flu/estimates_2009_h1n1. htm Accessed July 14, 2010. 
40. Reed C, Angulo FJ, Swerdlow DL, Lipsitch M, Meltzer MI, Jernigan D, Finelli L: Estimates of the prevalence of pandemic (H1N1) 2009, United States, April - July 2009. Emerg Infect Dis 2009, 49(12):1811-1820.

41. Centers for Disease Control and Prevention: Surveillance for pediatric deaths associated with 2009 pandemic influenza a (H1N1) virus infection - united states, April-August 2009. MMWR Morb Mortal Wkly Rep 2009, 58(34):941-947.

42. Morgan OW, Bramley A, Fowlkes A, Freedman DS, Taylor TH, Gargiullo P, Belay B, Jain S, Cox C, Kamimoto L, Fiore A, Finelli L, Olsen SJ, Fry AM: Morbid obesity as a risk factor for hospitalization and death due to 2009 pandemic influenza a(H1N1) disease. PLoS One 2010, 5(3):e9694.

43. Flegal KM, Carroll MD, Ogden CL, Curtin LR: Prevalence and trends in obesity among US adults, 1999-2008. JAMA 2010, 303(3):235-241.

44. Ray GT, Pelton SI, Klugman KP, Strutton D, Moore MR: Cost-effectiveness of pneumococcal conjugate vaccine: an update after years of use in the United States. Vaccine 2009, 27:6483-6494.

45. Louie JK, Acosta M, Winter K, Jean C, Gavali S, Schechter R, Vugia D, Harriman K, Matyas B, Glaser CA, Samuel MC, Rosenberg J, Talarico J, Hatch D, California Pandemic (H1N1) Working Group: Factors associated with death or hospitalization due to pandemic 2009 influenza $A(H 1 N 1)$ infection in California. JAMA 2009, 302(17):1896-1902.

46. Nguyen-Van-Tam JS, Openshaw PJ, Hashim A, Gadd EM, Lim WS, Semple MG, Read RC, Taylor BL, Brett SJ, McMenamin J, Enstone JE, Armstrong C, Nicholson KG, Influenza Clinical Information Network (FLU-CIN): Risk factors for hospitalisation and poor outcome with pandemic A/H1N1 influenza: United Kingdom first wave (MaySeptember 2009). Thorax 2010, 65(7):645-651.

47. Fiore AE, Shay DK, Broder K, Iskander JK, Uyeki TM, Mootrey G, Bresee JS, Cox NJ, Centers for Disease Control and Prevention: Prevention and control of seasonal influenza with vaccines: recommendations of the advisory committee on immunization practices (ACIP). MMWR Recomm Rep 2009, 58:1-52.

48. Melegaro A, Edmunds WJ: Cost-effectiveness analysis of pneumococcal conjugate vaccination in England and Wales. Vaccine 2004, 22(31-32):4203-4214.

49. Oostenbrook R, Moll H, Essink-Bot ML: The EQ-5D and the Health Utilities Index for permanent sequelae after meningitis: a head-to-head comparison. J Clin Epidemiol 2002, 55(8):791-799.

50. Erickson $L$, De Wals P, McMahon J, Heim S: Complications of meningococcal disease in college students. Clin Infect Dis 2001, 33(5):737-739.

doi:10.1186/1471-2334-13-229

Cite this article as: McGarry et al.: Impact of 13-valent pneumococcal conjugate vaccine (PCV13) in a pandemic similar to the $2009 \mathrm{H} 1 \mathrm{~N} 1$ in the United States. BMC Infectious Diseases 2013 13:229.

\section{Submit your next manuscript to BioMed Central and take full advantage of:}

- Convenient online submission

- Thorough peer review

- No space constraints or color figure charges

- Immediate publication on acceptance

- Inclusion in PubMed, CAS, Scopus and Google Scholar

- Research which is freely available for redistribution 